\title{
The Electrophoretic Properties and Some Surface Components of Penicillium Conidia
}

\author{
By D. J. FISHER AND D. V. RICHMOND \\ Long Ashton Research Station, University of Bristol, Bristol, BS I8 9AF \\ (Accepted for publication 13 October 1970) \\ SUMMAR Y
}

Conidia of Penicillium expansum are covered with a surface layer of polyphosphate when grown on a high phosphate medium. The composition of this polyphosphate layer, which appears 2 days after conidial initiation, is dependent on the phosphate content of the growth medium; the layer is absent from conidia grown on a low phosphate medium. The rodlet layer which lies beneath the polyphosphate is free of cutin and does not consist of a unique protein. The amino acid composition of the surface protein is, however, different from that of the total wall protein. The rodlet layer appears to be an integral part of the spore wall.

The $\mathrm{pH}$-mobility curves of Penicillium conidia are constant and speciesspecific when the fungi are grown on defined media.

\section{INTRODUCTION}

The chemical composition of hyphal cell walls has been studied in some detail (Bartnicki-Garcia, I968) but less attention has been paid to the physical and chemical properties of the spore wall. The composition of sporangiospore walls of Mucor rouxii (Bartnicki-Garcia \& Reyes, I964) and conidial walls of Aspergillus oryzae (Horikoshi \& Iida, 1964) have been investigated, while Rizza \& Kornfeld (1969) have compared the carbohydrate and amino acid composition of conidial and hyphal walls of Penicillium chrysogenum.

The surface ornamentation of fungal spores may be examined by the replica technique (Bigelow \& Rowley, 1968) or by freeze-etching (Laseter et al. 1968; Hess \& Stocks, 1969). The freeze-etching technique has shown that the surface of Penicillium conidia is covered with a distinctive pattern of rodlets (Hess, Sassen \& Remsen, I968).

Ionizable surface groups on fungal spores can be detected by particle electrophoresis in conjunction with chemical and enzymic treatments; the pH-mobility curves of fungal spores may be species specific. Conidia of Penicillium expansum are covered with a phosphate layer easily removed by washing to reveal an underlying aminocarboxyl surface (Fisher \& Richmond, 1969).

The purpose of the present paper is to describe further the surface components of Penicillium expansum conidia and to determine whether closely related species of Penicillium can be differentiated by their $\mathrm{pH}$-mobility curves. 


\section{METHODS}

Fungal material. Conidia from 7 day cultures of Penicillium expansum Link ex Thom, $P$. digitatum Sacc., $P$. roquefortii Thom, $P$. thomii Maire, kindly supplied by $\mathrm{Mr} \mathrm{R}$. C. Codner of the University of Bath, and $P$. notatum Westling (CM I I7969), from the Commonwealth Mycological Institute, were grown on malt agar and harvested as previously described (Richmond \& Somers, I963). Cultures of $P$. expansum were also grown on Fries medium (Richmond \& Somers, 1962) containing $0.3,3 \cdot 0$ and $6.0 \mathrm{~g}$. $\mathrm{KH}_{2} \mathrm{PO}_{4} / 1$. The $\mathrm{pH}$ of this medium was adjusted to $6 \cdot 0$. Spore walls were obtained by shaking dense spore suspensions with an equal volume of ballotini (no. 12) in a Mickle disintegrator at $4^{\circ}$ for $15 \mathrm{~min}$. (Somers \& Fisher, 1967). The centrifuged walls were washed ten times with $10 \%(\mathrm{w} / \mathrm{v})$ sucrose, five times with $0.9 \%(\mathrm{w} / \mathrm{v}) \mathrm{NaCl}$ and five times with water following the technique of Dyke (1964). The final washing was free of u.v. absorbing material.

Examination of water-soluble wall components. Soluble surface material was removed from conidia by repeated washing with water or by using the Dyke (1964) technique (described above). Polyphosphates and sugars were examined in the combined water washings after concentration to $5 \mathrm{ml}$. in a rotary evaporator at $40^{\circ}$.

Polyphosphates were identified by thin-layer chromatography on starch (Canic, Turčic, Petrovic \& Petrovic, 1965). The solvent system was trichloroacetic acid +iso-

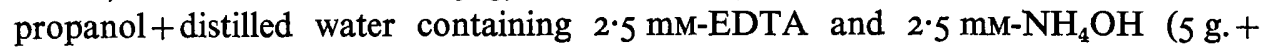
$80 \mathrm{ml} .+40 \mathrm{ml}$.). Polyphosphates were detected by spraying the plate with molybdateperchloric acid (Hanes \& Isherwood, 1949). For the determination of metachromatic activity, polyphosphates were precipitated from the concentrated spore washings by a saturated solution of barium acetate. The precipitate was washed, resuspended in $5 \mathrm{ml}$. water and shaken with $200 \mathrm{mg}$. Amberlite resin I R-I $20\left(\mathrm{H}^{+}\right.$form). The bariumfree solution was examined for metachromatic activity with $0.006 \%(\mathrm{w} / \mathrm{v})$ aqueous toluidine blue (Nassery, 1969). The values of $E_{530} / E_{630}$ were then calculated. Total phosphorus was determined by the method of Hanson (1950) after digestion with $\mathrm{HNO}_{3}$ followed by $\mathrm{HClO}_{4}$.

Sugars in the soluble surface material were examined after hydrolysis in $0.5 \mathrm{M}$ $\mathrm{H}_{2} \mathrm{SO}_{4}$ for $12 \mathrm{~h}$. at $105^{\circ}$ in a sealed tube. Excess sulphate was removed by precipitation with barium hydroxide and the supernatant solution was passed down columns of Amberlite IR-I $20\left(\mathrm{H}^{+}\right.$form) and 400 (acetate form). Total reducing sugars were determined by the arsenomolybdate method (Chan \& Cain, 1966). Individual monosaccharides were identified by paper chromatography. The solvent system was secbutanol + acetic acid + water $(70+2+28, v / v)$. Sugars were detected by spraying the paper with $p$-anisidine (Mukherjee \& Srivastava, 1952).

Examination of surface protein. Surface protein was extracted from spores by incubating with urea $(7 \mathrm{M}, \mathrm{pH} 2.8)$ containing $10 \%(\mathrm{w} / \mathrm{v})$ 2-mercaptoethanol for $\mathrm{I} h$. at $37^{\circ}$. The suspension was cooled and centrifuged, and the spores were washed four times with water then incubated with $0 . \mathrm{I} \mathrm{M-NaOH}$ for $15 \mathrm{~min}$. at $4^{\circ}$. The alkaline extract was dialysed against running water overnight (Gould, Stubbs \& King, 1970).

Amino acids in the extracted non-dialysable wall material were determined on a Technicon TSM.I amino acid analyser after hydrolysis with $6 \mathrm{M}-\mathrm{HCl}$ at $100^{\circ}$ in an atmosphere of $\mathrm{N}_{2}$ for $2 \mathrm{I} \mathrm{h}$.

Total protein. Total protein was determined by the method of Lowry, Rosebrough, 
Farr \& Randall (I95I) after treatment of the walls with $2 \mathrm{M}-\mathrm{NaOH}$ at $100^{\circ}$ for $30 \mathrm{~min}$. (Shah \& Knight, 1968).

Detection of cutin acids. Washed spore walls were refluxed with I \% ethanolic $\mathrm{KOH}$ for $3 \mathrm{~h}$. The fatty acids were extracted with ether, methylated with diazomethane and examined by thin-layer chromatography on Kieselguhr HR using chloroform + ethyl acetate $(7+3)$ as solvent or by gas-liquid chromatography using a Hewlett-Packard 5750 gas chromatograph (Baker \& Holloway, 1970).

Freeze-etching. Conidia were suspended in $15 \%$ glycerol for $\mathrm{I} h$., centrifuged into a pellet, frozen in liquid Freon 12 at $-150^{\circ}$ and then treated as described by Moor (1966). Replicas were prepared in a Balzers freeze-etching plant BA $360 \mathrm{M}$ and viewed in an AEI EM6B microscope.

Electrophoretic measurements. The electrophoretic mobilities of conidia were measured in a laterally mounted rectangular cell enclosed in a water bath maintained at $25.0 \pm 0 \cdot 2^{\circ}$ (Fisher \& Richmond, I969). Measurements were made on conidia which had been washed once with the appropriate buffer before suspension in $\mathrm{HCl}+\mathrm{NaCl}$ or barbiturate + acetate buffer (I: 0.05) of the required pH (Gittens \& James, 1963). Movement was timed over $\mathrm{I} 80 \mu \mathrm{m}$. in both directions (current reversal). Each mobility was the mean of at least 20 observations; the standard error of the mean was less than $4 \%$. Mobilities are expressed as $10^{-8} \mathrm{~m}^{2} \mathrm{~V}^{-1} \mathrm{~s}^{-1}$ (equivalent to $\mu \mathrm{m} . \mathrm{cm} . \mathrm{V}^{-1}$ s. ${ }^{-1}$ in c.g.s. units).

\section{RESULTS}

Electrophoretic properties of Penicillium conidia. The $\mathrm{pH}-$ mobility curves of conidia from five species of Penicillium grown on malt agar were all different and characteristic (Fig. I). The pH-mobility curves were affected neither by repeated reculturing of the fungi nor by storage of conidia in water for up to 2 days. There was no evidence to suggest that suspension of conidia in the acid or alkaline buffers caused any surface denaturation; after suspension in $\mathrm{pH} 7.0$ buffer, mobilities were the same as those of normal control conidia. A single washing in buffer before mobilities were determined was necessary to ensure complete removal of water from the conidia, but this washing had no effect on mobility; conidia shaken dry from culture plates had the same mobility as conidia harvested by the normal procedure.

Effect of age on $\mathrm{pH}$-mobility curve of conidia of Penicillium expansum. The $\mathrm{pH}-$ mobility curve of I day conidia grown on malt agar had a typical amino-carboxyl shape with an iso-potential point at $\mathrm{pH}_{3.5}$ (Fig. 2). After 2 days the $\mathrm{pH}$-mobility curve (Fig. 2) showed an acid surface with an iso-potential point of $2 \cdot 0$ closely resembling that from 7 day conidia (Fig. I). As the shape of the $\mathrm{pH}$-mobility curve showed little change after 2 days, all further tests were carried out on 7 day cultures.

Influence of growth medium on $\mathrm{pH}$-mobility curve. The $\mathrm{pH}$-mobility curve of conidia grown on Fries medium $\left(3.0 \mathrm{~g}\right.$./1. $\left.\mathrm{KH}_{2} \mathrm{PO}_{4}\right)$ was quite different from that of conidia grown on malt agar and indicated an amino-carboxyl surface (Fig. 3). When the phosphate content of the Fries medium was reduced to $0.03 \mathrm{~g}$. $/ 1$. $\mathrm{KH}_{2} \mathrm{PO}_{4}$ the pHmobility curve had a similar shape although mobilities were higher above $\mathrm{pH}_{7}{ }^{\circ}$. When the phosphate content of the medium was increased to $6.0 \mathrm{~g} . / 1 . \mathrm{KH}_{2} \mathrm{PO}_{4}$ an entirely acid surface was formed (Fig. 3).

Effect of washing on pH-mobility curve. The surface of conidia grown on malt agar became progressively less acid as the conidia were washed, until a typical amino- 
carboxyl surface was revealed (Table $\mathrm{I}$ ). The rapid increase in iso-potential point from 2.0 to 3.4 after only five washings shows that most surface phosphate was easily removable. Further washings produced only a small increase in iso-potential point, but the large increase in positive mobility at $\mathrm{pH} 2.0$ and the similar increase in negative at $\mathrm{pH} 5.0$ suggests that prolonged washing removed non-ionogenic material. When conidia grown on Fries medium with the highest phosphate content were washed the

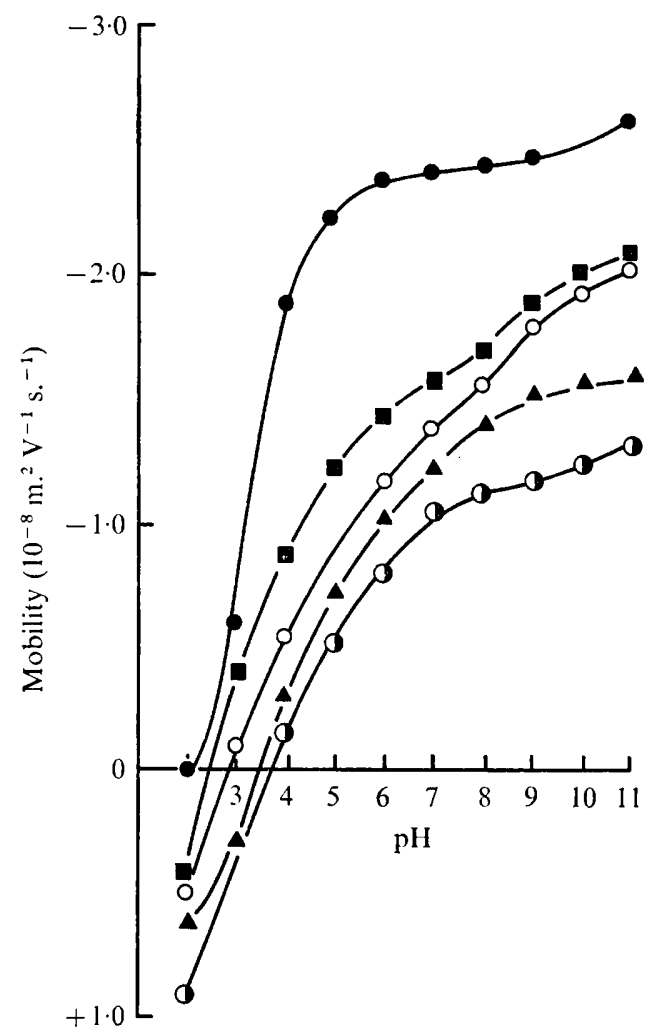

Fig. I

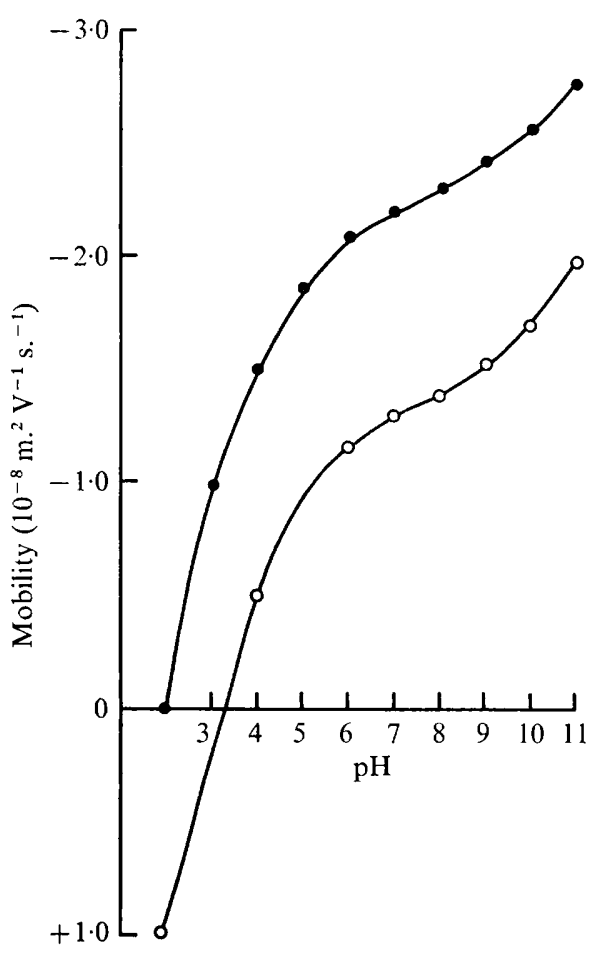

Fig. 2

Fig. I. pH-mobility curves of Penicillium expansum, - $-P$. thomii, $\square-\square ; P$.

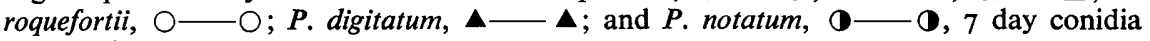
from malt agar.

Fig. 2. pH-mobility curves of Penicillium expansum, I day conidia, $\bigcirc-\bigcirc ; 2$ day conidia, - - , from malt agar.

Table I. Mobilities of washed conidia of Penicillium expansum grown on malt agar

\begin{tabular}{|c|c|c|c|c|c|}
\hline \multirow[b]{2}{*}{ Washing procedure } & \multirow{2}{*}{$\begin{array}{l}\text { Iso-potential } \\
\text { point }(\mathrm{pH})\end{array}$} & \multicolumn{4}{|c|}{ Mobilities $\left(\mathrm{IO}^{-8} \mathrm{~m}^{2} \mathrm{~V}^{-1} \mathrm{~s}^{-1}\right)$} \\
\hline & & $\mathrm{pH} 2 \cdot 0$ & $\mathrm{pH} 3 \cdot 0$ & $\mathrm{pH}_{4} \cdot \mathrm{O}$ & $\mathrm{pH} 5.0$ \\
\hline Control unwashed & $2 \cdot 0$ & 0.00 & -0.60 & $-I \cdot 87$ & $-2 \cdot 23$ \\
\hline Water $(\times 5)$ & $3 \cdot 4$ & +0.25 & +0.08 & -0.13 & -0.36 \\
\hline Water $(\times 10)$ & 3.5 & +0.55 & +0.24 & -0.21 & -0.42 \\
\hline Water $(\times 15)$ & $3 \cdot 6$ & +0.63 & +0.37 & -0.33 & $-0.7 \mathrm{r}$ \\
\hline $\begin{array}{ll}10 \% \text { Sucrose } & (\times 10) \\
0.9 \% \mathrm{NaCl} & (\times 5) \\
\text { Water } & (\times 5)\end{array}$ & 3.7 & $+\mathrm{r} \cdot 08$ & +0.77 & -0.55 & $-1 \cdot 10$ \\
\hline
\end{tabular}


acid surface was only partially removed even after prolonged washing (Fig. 4). The acid groups appeared to have become an integral part of the surface possibly because the polyphosphate was present in a higher polymeric form.

Composition of spore washings. The amount of phosphorus compounds washed from Penicillium expansum conidia varied widely with the nature and phosphorus content of the medium (Table 2). The small amount of phosphorus removed from conidia

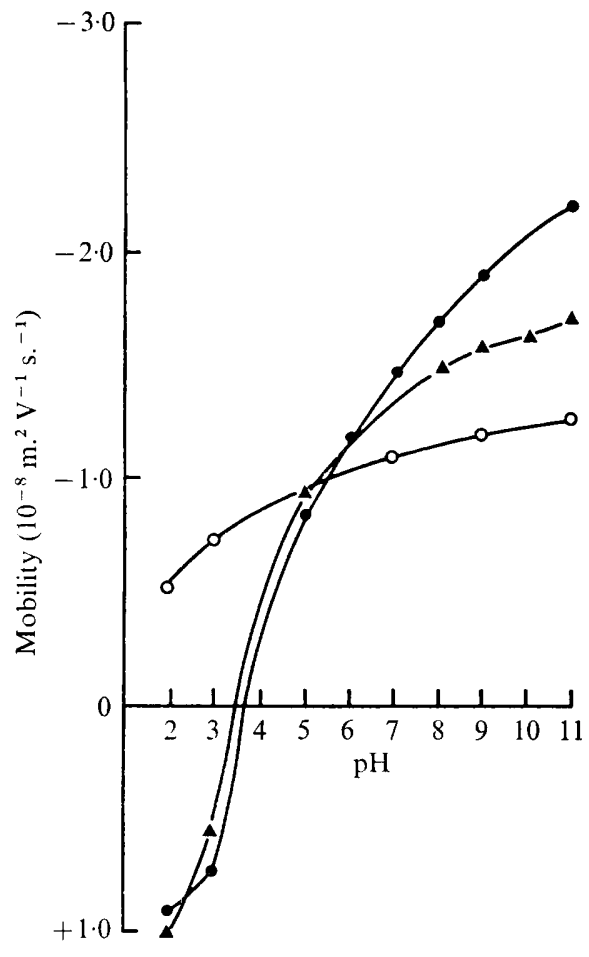

Fig. 3

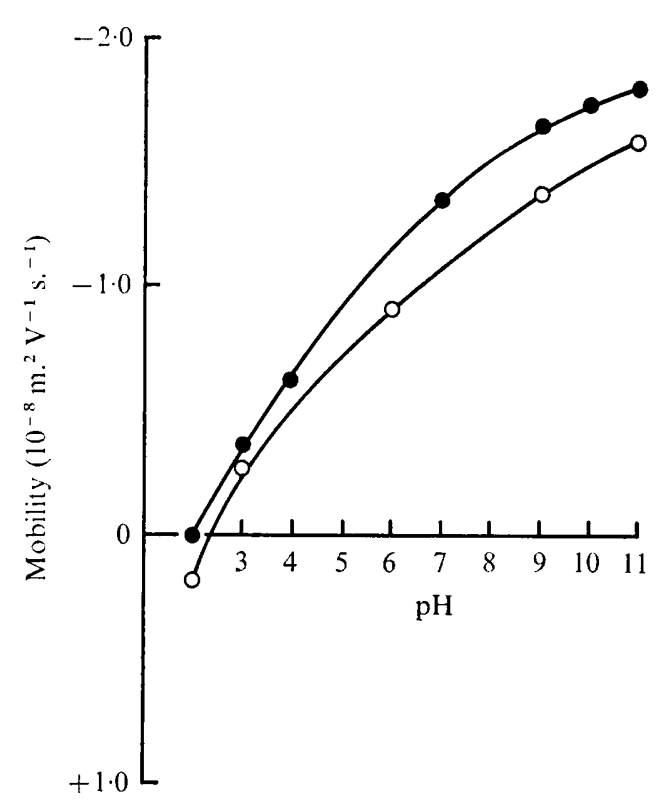

Fig. 4

Fig. 3. pH-mobility curves of Pencillium expansum grown on Fries medium, containing

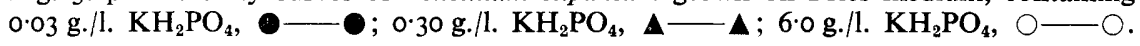

Fig. 4. pH-mobility curves of Penicillium expansum grown on Fries medium containing 6.0 g./l. $\mathrm{KH}_{2} \mathrm{PO}_{4}$, conidia washed ten times with $10 \%(\mathrm{w} / \mathrm{v})$ sucrose, five times with $0.9 \%$ $(\mathrm{w} / \mathrm{v}) \mathrm{NaCl}$ and five times with water, $\mathrm{O}-\mathrm{O}$.

grown on Fries medium with the highest phosphate content is in agreement with the electrophoretic results which showed that even prolonged washing had little effect on the acid surface (Fig. 4). The metachromatic activity of the washings established that polyphosphates were present on all conidial surfaces. The highest polyphosphate content occurred on conidia grown on malt agar but small amounts were present on conidia grown on Fries medium. Conidial production was greater on malt agar than on Fries medium, even when the phosphorus contents of the two media were similar. Thin-layer chromatography of the concentrated water washings from conidia grown on malt agar confirmed the presence of polyphosphates and showed them to contain less than ten phosphorus atoms. The extracted material was free of nucleic acid, having 
no absorption at $260 \mathrm{~nm}$., and imidophosphate linkages were absent as no infrared absorption peak occurred at $7 \cdot 15 \mu \mathrm{m}$. (Correll, I966).

As prolonged washing of conidia grown on malt agar seemed to remove nonionogenic material (Table I) the water washings were examined for carbohydrates. The total reducing sugars (as glucose) from 20 successive water washes was $7^{\cdot} \mathrm{I} \mu \mathrm{g}$. $/ \mathrm{g}$. dry wt of spores before hydrolysis and $12.6 \mu \mathrm{g}$./g. after. Glucose and xylose were present before hydrolysis and, in addition, arabinose after hydrolysis.

\section{Table 2. The effect of growth medium on the phosphorus content of conidia and conidial washings from Penicillium expansum}

Conidia were grown, harvested and washed as described in the text.

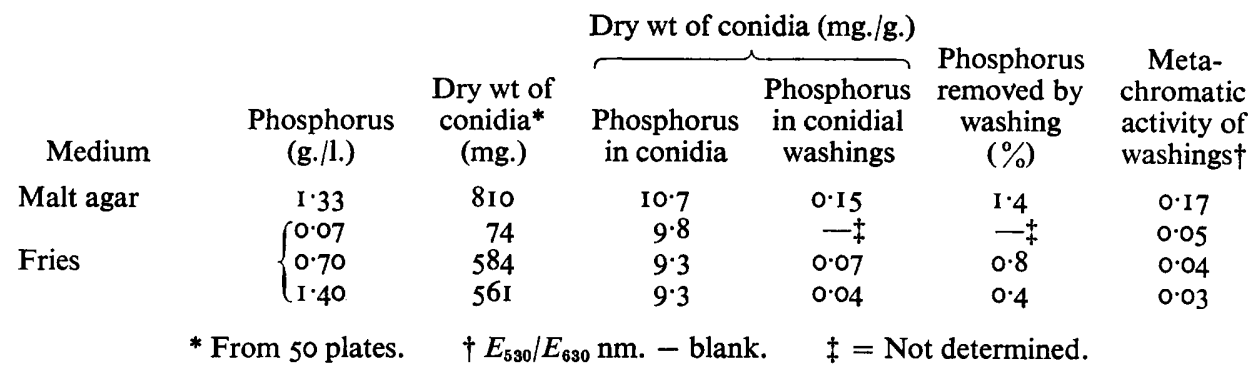

Nature of the rodlet layer. Hess et al. (1968) suggested that the outer rodlet layer on Penicillium conidia might consist of cutin or a similar material, since they found the layer to be removed by treatment with aqueous or ethanolic $\mathrm{KOH}$. None of the hydroxy fatty acids characteristic of cutin (Baker \& Holloway, 1970) could be detected in ethanolic $\mathrm{KOH}$ wall extracts either by thin-layer or by gas-liquid chromatography. The fatty acids extracted from the cell walls after methylation and analysis by gas-liquid chromatography consisted mainly of palmitic ( $46.5 \%$ of total peak area), oleic ( $19.9 \%$ ) and stearic (19.5\%) acids, although five other acids were present in small amounts. Although many studies have been made on the lipid composition of fungi (Shaw, I966) less work has been done on isolated cell walls. Laseter, Weete \& Weber (I968) have, however, found that palmitic and oleic acids were the most abundant fatty acids in the surface wax from chlamydospores of Ustilago maydis.

The rodlets on freeze-etched Pencillium conidia closely resemble the patterns seen on some bacterial spores (Holt \& Leadbetter, 1969). The patterned surface layer on Bacillus coagulans spores consists of an alkali-soluble protein which can be removed from the spores by treatments which rupture disulphide bonds (Gould et al. 1970). Examination of freeze-etched replicas of Penicillium expansum conidia showed that the surface rodlets were not removed by incubation with mercaptoethanol in urea followed by treatment with $0.1 \mathrm{M}-\mathrm{NaOH}$. The rodlets were, however, less distinct after alkali treatment, suggesting that some protein material may have been removed. The electrophorectic mobility of water-washed conidia fell, after alkali treatment, from $-2 \cdot 0$ to $-\mathrm{I} \cdot \mathrm{I} 6 \times \mathrm{IO}^{-8} \mathrm{~m} .^{2} \mathrm{~V}^{-1} \mathrm{s.}^{-1}$ at $\mathrm{pH} \mathrm{I0} \cdot 0$ and from $+\mathrm{I} \cdot \mathrm{I}$ to $+0.64 \times \mathrm{IO}^{-8} \mathrm{~m}^{2}$ $\mathrm{V}^{-1} \mathrm{~s}^{-1}$ at $\mathrm{pH} 2 \cdot 0$. The iso-potential point was the same in control and treated spores. The decreases in mobility confirm that the treatment may have partially removed some protein material. Analysis of the non-dialysable alkali-soluble material showed it to contain $I I \cdot 2 \%$ protein. The remainder of the extracted material probably consisted 
of polymeric polysaccharides (Grisaro, Sharon \& Barkai-Golan, 1968). The extracted protein which represents only a small proportion of the total conidial wall protein (Table 3) had a high tyrosine and methionine content, proline was absent, and threonine, leucine, isoleucine, histidine, valine and cyst(e)ine were low as compared with conidial wall protein (Table 4). The distinctive amino acid composition of the extracted protein confirmed the partial removal of a definite surface layer. The total conidial wall protein was similar in composition to the cytoplasmic protein. Mercaptoethanol pretreatment had little effect on the removal of surface protein and the amino acid composition of the alkaline extract was the same whether mercaptoethanol was used or not.

Table 3. Some components of conidial walls of Penicillium expansum grown on malt agar

$\begin{array}{lc} & \% \\ \text { Protein } & 7 \cdot 67 \\ \text { Phosphorus } & 0 \cdot 23 \\ \text { Nitrogen (by Kjeldahl) } & 3.32 \\ \text { Alkali-soluble surface protein } & 0 \cdot 37 \\ \text { Other alkali-soluble material } & 2 \cdot 92\end{array}$

Table 4. Amino acid components of Penicillium expansum conidia

\begin{tabular}{|c|c|c|c|}
\hline \multirow[b]{2}{*}{ Amino acid } & \multicolumn{3}{|c|}{ Mole ratio } \\
\hline & $\begin{array}{l}\text { Alkaline extract } \\
\text { from conidia }\end{array}$ & Conidial wall & Cytoplasm \\
\hline Aspartic acid & I. 38 & I.25 & I $\cdot 24$ \\
\hline Glutamic acid & $1 \cdot 48$ & $1 \cdot 13$ & $I \cdot I I$ \\
\hline Threonine & 0.50 & I.07 & 0.84 \\
\hline Serine & 1.00 & $I \cdot 10$ & $I \cdot I 4$ \\
\hline Alanine & $I \cdot 00$ & $I \cdot 00$ & 1.00 \\
\hline Glycine & $I \cdot 13$ & $\mathrm{I} \cdot 02$ & 0.85 \\
\hline Leucine & 0.49 & 0.76 & 0.74 \\
\hline Phenylalanine & 0.40 & $0.3 \mathrm{I}$ & 0.40 \\
\hline Lysine & 0.26 & $0.3 \mathrm{I}$ & 0.20 \\
\hline Isoleucine & 0.18 & 0.39 & 0.23 \\
\hline Arginine & 0.43 & 0.50 & 0.48 \\
\hline Tyrosine & 1.09 & $0.3 \mathrm{I}$ & 0.36 \\
\hline Proline & n.d. & 0.77 & $0.5 \mathrm{I}$ \\
\hline Histidine & 0.30 & $0.6 \mathrm{I}$ & 0.53 \\
\hline Valine & 0.34 & 0.72 & 0.48 \\
\hline Half cystine & 0.23 & $1 \cdot 30$ & $\mathrm{I} \cdot 78$ \\
\hline Methionine & 0.86 & 0.13 & 0.13 \\
\hline
\end{tabular}

\section{DISCUSSION}

It is at first sight surprising that closely related species should have such widely different mobility curves; the explanation probably lies in the presence of a polyphosphate layer which is not an integral part of the conidial surface.

The presence of surface phosphate on conidia of Penicillium expansum was previously demonstrated by treatment with acid phosphatase and confirmed by the decrease in mobility at $\mathrm{pH} 7.0$ which occurred in the presence of $\mathrm{Ca}^{2+}$. Removal of phosphate by enzyme action or prolonged washing revealed an underlying amino-carboxyl surface 
(Fisher \& Richmond, 1969). The curves of the other Penicillium species (Fig. I) are indicative of amino-carboxyl surfaces containing varying amounts of phosphate. The curve of $P$. notatum is remarkably similar to that of $P$. expansum after complete phosphate removal (Fisher \& Richmond, 1969).

No imidophosphate linkages or nucleic acids were detected in extracts from Penicillium expansum conidia and phospholipids are absent as the surface is lipid-free (Fisher \& Richmond, 1969). Although surface phosphate groups have been detected on yeast cells (Eddy \& Rudin, I958) and Neurospora crassa conidia (Somers \& Fisher, I967) as well as on $P$. expansum conidia (Fisher \& Richmond, I969), the exact nature of the phosphate was not specified. Rothstein \& Meier (195I) have, however, suggested that uranyl ions may react with polyphosphate-like groups on the yeast surface, and Harold (1962) has shown that cytoplasmic polyphosphate can bind to hyphal walls of $N$. crassa.

The Penicillium conidium has a three-layered wall covered with an outer patterning of rodlets (Sassen, Remsen \& Hess, I967). Carbon replica studies suggest that the rodlets are themselves covered with an additional very thin film (Hess et al. 1968). This film may constitute the polyphosphate layer present on unwashed conidia. Our results show that the polyphosphate layer is not an integral part of the conidial surface. Eddy \& Rudin (1958) also found that phosphate groups were absent from the surface of cells grown in phosphate-deficient media.

No specific function can, at present, be suggested for the surface polyphosphate which may act simply as an inorganic phosphate reserve (Harold, I966). Alternatively, polyphosphate may be implicated in phosphorylation reactions involved in the transport of glucose into the cell on germination (Rothstein \& Meier, 195I).

The presence of free xylose in the carbohydrate layer of conidia is of interest. Xylose has been found in hyphal walls of Penicillium chrysogenum (Hamilton \& Knight, 1962), $P$. digitatum and $P$. italicum (Grisaro et al. 1968). Rizza \& Kornfeld (1969) were, however, unable to detect xylose in either hyphal or conidial walls of $P$. chrysogenum. Arabinose which was found in the carbohydrate layer after hydrolysis has also been found in small amounts in hyphal walls of Aspergillus niger (Johnston, 1965).

The rodlet layer appears to be an integral part of the wall structure since it is not easily separated from the rest of the wall by mechanical disruption. This layer is free of cutin and is not composed of a unique protein. The surface layer does, however, contain protein of a different amino acid composition from that present in the whole wall. The amino acid composition of the whole conidial wall is similar to that of the hyphal wall of Penicillium notatum (Applegarth, 1967) except for the presence of valine. Conidial walls of $P$. chrysogenum are, however, quite distinct, since tyrosine, phenylalanine, methionine and histidine are absent (Rizza \& Kornfeld, I969). Fungal cell walls have frequently been reported to contain a full complement of amino acids (Crook \& Johnston, 1962; Shah \& Knight, 1968; Aronson \& Fuller, 1969).

The high tyrosine and methionine content of the surface protein may be significant. Tyrosine is a precursor of melanin, which can protect fungi from enzymic lysis (Kuo \& Alexander, I967; Bull, I970), while methionine as $S$-adenosylmethionine, an important methyl donor in plants (Meister, 1965), may detoxify injurious substances. Although the rodlet layer superficially resembles the surface layer of Bacillus coagulans spores (Gould et al. 1970), the two layers are different in structure and composition.

Water repellency can probably be attributed to the rodlet layer. The polyphosphate 
layer does not contribute materially to the water-repellent properties of the spores since conidia grown on low-phosphate media lack polyphosphate and are still waterrepellent.

The Penicillium spore surface has previously been shown to be lipid-free (Fisher \& Richmond, 1969); the present work has not found any other substances which could be responsible for water-repellency. The physical conformation of the surface may itself be sufficient to prevent wetting.

We would like to thank Dr P. J. Holloway for the gas-liquid chromatography and Dr M. J. A. Tanner of the Biochemistry Department, University of Bristol, for the amino acid analyses; also Dr G. W. Gould and Mr E. A. Baker for kindly letting us see their papers prior to publication. We are indebted to $\mathrm{Mr} \mathrm{T}$. Thomas for valuable technical assistance.

\section{REFERENCES}

Applegarth, D. A. (1967). The cell wall of Penicillium notatum. Archives of Biochemistry and Biophysics 120, 47I-478.

Aronson, J. M. \& Fuller, M. S. (1969). Cell wall structure of the marine fungus, Atkinsiella dubia. Archiv für Mikrobiologie 68, 295-305.

Baker, E. A. \& Holloway, P. J. (1970). The constituent acids of angiosperm cutins. Phytochemistry 9, I557-I 562 .

BARTNICKI-GARCIA, S. (1968). Cell wall chemistry, morphogenesis, and taxonomy of fungi. Annual Review of Microbiology 22, 87-108.

BarTNICKI-GARCIA, S. \& ReYeS, S. (1964). Chemistry of spore wall differentiation in Mucor rouxii. Archives of Biochemistry and Biophysics 108, I25-1 33.

Bigelow, H. E. \& Rowley, J. R. (I968). Surface replicas of the spores of fleshy fungi. Mycologia 6o, 869-887.

Bull, A. T. (1970). Inhibition of polysaccharases by melanin: enzyme inhibition in relation to mycolysis. Archives of Biochemistry and Biophysics 137, 345-356.

Canic, V. D., Turčic, M. N., Petrovic, S. M. \& Petrovic, S. E. (1965). Separation of condensed phosphates on thin layer of starch. Analytical Chemistry 37, I 576-1 577.

Chan, B. G. \& CaIN, J. C. (I966). A rapid quantitative method for routine determination of monosaccharides and oligosaccharides from plants by paper chromatography. Journal of Chromatography 22, 95-IOI.

CORRell, D. L. (1966). Imidonitrogen in chlorella 'Polyphosphate'. Science, New York 15I, 819-82I.

Crook, E. M. \& Johnston, I. R. (1962). The qualitative analysis of the cell walls of selected species of fungi. Biochemical Journal 83, 325-331.

Dyke, K. G. H. (I964). The chemical composition of the cell wall of the yeast Nadsonia elongata. Biochimica et biophysica acta 82, 374-384.

EdDy, A. A. \& Rudin, A. D. (1958). The structure of the yeast cell wall. I. Identification of charged groups at the surface. Proceedings of the Royal Society, B r48, 419-432.

FISHER, D. J. \& RICHMOND, D. V. (I969). The electrokinetic properties of some fungal spores. Journal of General Microbiology 57, $51-60$.

GitTens, G. J. \& JAMES, A. M. (1963). Some physical investigations of the behaviour of bacterial surfaces. VI. Chemical modification of surface components. Biochimica et biophysica acta 66, 237-249.

Gould, G. W., StubBs, J. M. \& KING, W. L. (1970). Structure and composition of resistant layers in bacterial spore coats. Journal of General Microbiology 6o, 347-355.

Grisaro, V., Sharon, N. \& BarkaI-Golan, R. (1968). The chemical composition of the cell walls of Penicillium digitatum Sacc. and Penicillium italicum Whem. Journal of General Microbiology 5I, I45-150.

Hamilton, P. B. \& KNIGHT, S. G. (1962). An analysis of the cell walls of Penicillium chrysogenum. Archives of Biochemistry and Biophysics 99, 282-287. 
HANes, C. S. \& IsheRwood, F. A. (1949). Separation of the phosphoric esters on the filter paper chromatogram. Nature, London I64, I I07-I I 2.

Hanson, W. C. (1950). The photometric determination of phosphorus in fertilizers using the phosphovanado-molybdate complex. Journal of the Science of Food and Agriculture r, 172-177.

HAROLD, F. M. (1962). Binding of inorganic polyphosphate to the cell wall of Neurospora crassa. Biochimica et biophysica acta 57, 59-66.

HAROLD, F. M. (1966). Inorganic polyphosphates in biology: structure, metabolism, and function. Bacteriological Reviews 30, 772-794.

Hess, W. M., SASSEN, M. M. A. \& REMSEN, C. C. (1968). Surface characteristics of Penicillium conidia. Mycologia 60, 290-303.

Hess, W. M. \& Stocks, D. L. (1969). Surface characteristics of Aspergillus conidia. Mycologia 6r, 560-57I.

Holt, S. C. \& LeAdbetrer, E. R. (1969). Comparative ultrastructure of selected aerobic sporeforming bacteria: a freeze-etching study. Bacteriological Reviews 33, 346-378.

HoRIKoshi, K. \& IDA, S. (I964). Studies of the spore coats of fungi. I. Isolation and composition of the spore coats of Aspergillus oryzae. Biochimica et biophysica acta 83, 197-203.

Johnston, I. R. (1965). The composition of the cell wall of Aspergillus niger. Biochemical Journal 96, 65I-658.

Kuo, M. J. \& AleXANDer, M. (1967). Inhibition of the lysis of fungi by melanins. Journal of Bacteriology 94, 624-629.

Laseter, J. L., Hess, W. M., Weete, J. D., Stocks, D. L. \& Weber, D. J. (1968). Chemotaxonomic and ultrastructural studies on three species of Tilletia occurring on wheat. Canadian Journal of Microbiology I4, II 49-I 154.

LASETER, J. L., WEETE, J. \& WEBER, D. J. (I968). Alkanes, fatty acid methyl esters, and free fatty acids in surface wax of Ustilago maydis. Phytochemistry $7,1177-1$ I 81 .

Lowry, H. O., Rosebrough, N. J., Farr, A. L. \& Randall, R. J. (195I). Protein measurement with the folin phenol reagent. Journal of Biological Chemistry 193, 265-275.

MeIster, A. (1965). Biochemistry of the Amino Acids, 2nd edn, vol. 2, p. 768 . New York: Academic Press.

MooR, H. (1966). Use of freeze-etching in the study of biological ultrastructure. International Review of Experimental Pathology 5, 179-216.

MukHerJeE, S. \& SRIvastava, H. C. (1952). Improved spray reagent for the detection of sugars. Nature, London 169, 330.

NASSERY, H. (1969). Polyphosphate formation in the roots of Deschampsia flexuosa and Urtica dioica. New Phytologist 68, $2 \mathrm{I}-23$.

Richmond, D. V. \& Somers, E. (1962). Studies on the fungitoxicity of captan. I. The structural specificity of captan and six $n$-trichloromethylthio analogues. Annals of Applied Biology 50, 33-43.

RICHMOND, D. V. \& Somers, E. (1963). Studies on the fungitoxicity of captan. III. Relation between the sulphydryl content of fungal spores and their uptake of captan. Annals of Applied Biology $52,327-336$.

RizzA, V. \& KoRnFeld, J. M. (1969). Components of conidial and hyphal walls of Penicillium chrysogenum. Journal of General Microbiology 58, 307-315.

ROTHSTEIN, A. \& MEIER, R. (195I). The relationship of the cell surface to metabolism. VI. The chemical nature of uranium-complexing groups of the cell surface. Journal of Cellular and Comparative Physiology 38, 245-270.

Sassen, M. M. A., Remsen, C. C. \& Hess, W. M. (1967). Fine structure of Penicillium megasporum conidiospores. Protoplasma 64, 75-88.

ShAH, V. K. \& KNIGHT, S. G. (1968). Chemical composition of hyphal walls of dermatophytes. Archives of Biochemistry and Biophysics 127, 229-234.

Shaw, R. (1966). The polyunsaturated fatty acids of micro-organisms. Advances in Lipid Research 4, I07-174.

SOMERS, E. \& FISHER, D. J.(1967). Effect of dodine acetate on the electrophoretic mobility of Neurospora crassa conidia. Journal of General Microbiology 48, 147-154. 